\title{
LEPTOSPIROSE BOVINA: SOROLOGIA NA BACIA LEITEIRA DA REGIÃO DE LONDRINA, PARANÁ, BRASIL
}

\author{
BOVINE LEPTOSPIROSIS: SEROLOGY AT DAIRY FARMS \\ IN LONDRINA REGION, PARANÁ STATE, BRAZIL
}

\author{
Cibele Giatti Rodrigues ${ }^{1}$ Ernst Eckehardt Müller ${ }^{2}$ Julio Cesar de Freitas ${ }^{3}$
}

Uma avaliação sorológica para 22 sorotipos de $\boldsymbol{L}$ interrogans foi realizada. Usou-se o teste de microaglutinação rápida no soro de 1253 fêmeas bovinas, adultas de 14 propriedades produtoras de leite tipo $B$, da região de Londrina-ParanáBrasil, onde havia animais com problemas reprodutivos. Títulos de anticorpos $\geq 100$ foram detectados em 166 (13,25\%) animais de 10 (71,43\%) propriedades. Em 56 (33,73\%) animais foram encontrados anticorpos contra dois ou mais sorotipos simultaneamente. Anticorpos contra o sorotipo icterohaemorrhagiae foram detectados em $48(28,91 \%)$ animais, seguido pelos sorotipos pomona 35 (21,08\%); bataviae 28 (16,87\%); autumnalis 24 (14,46\%); canicola 19 (11,44\%); hardjo 18 (10,84\%); bratislava 17 (10,24\%); butembo 13 (7,83\%); pyrogenes 12 (7,22\%); hebdomadis $11(6,63 \%)$ e wolffi $10(6,02 \%)$.

Palavras-chave: bovino, Leptospira interrogans, sorologia.

\section{SUMMARY}

A serological survey for leptospirosis was performed in farms that had cows with reproductive problems, in the region of Londrina, Paraná State, Brazil. Twenty-two serotype of $\boldsymbol{L}$. interrogans were investigated, using rapid microscopic agglutination test in 1253 serum samples. One-hundred-sixty-six serum samples (13.25\%) from 10 farms $(71.43 \%)$ presented antibodies agaisnt L. interrogans. Antibodies against two or more $\boldsymbol{L}$. interrogans serotypes were found in 56 animals. Antibodies against the serotype icterohaemorrhagiae were found in $48(28.91 \%)$ animals, whereas antibodies against pomona were found in $35(21.08 \%)$, bataviae in 28 (16.87\%), autumnalis in $24(14.46 \%)$, canicola in $19(11.44 \%)$, hardjo in $18(10.84 \%)$, bratislava in $17(10.24 \%)$, butembo in $13(7.83 \%)$, pyrogenes in $12(7.22 \%)$, hebdomadis in $11(6.63 \%)$ and wolffi in $10(6.02 \%)$.
Key words: bovine, Leptospira interrogans, serological survey.

\section{INTRODUÇÃO}

A leptospirose bovina encontra-se amplamente difundida no mundo. Levantamentos sorológicos estimam uma prevalência de $15,0 \%$ no rebanho bovino norte americano (THIERMANN, 1984). No Brasil, os resultados sorológicos de bovinos obtidos por vários autores (ÁVILA et al., 1978; MOREIRA et al., 1979; GIORGI et al., 1981; RIBEIRO et al., 1988; GIRIO \& MATHIAS, 1989; BROD et al., 1995) também mostraram que a infecção está bastante difundida. Segundo TEDESCO (1997), a leptospirose em bovinos é uma doença ainda em expansão em nosso país. Atualmente, o sorotipo hardjo tem sido o mais freqüentemente detectado e o que causa maior impacto econômico na eficiência reprodutiva de rebanhos de bovinos de diversas partes do mundo ( SALMAN, 1990; MILLER et al., 1991; MOREIRA et al. 1993; MOREIRA et al., 1994; BROD et al., 1995; LILENBAUM et al., 1995; RICHARDSON, 1995; TEDESCO, 1997). Nessa espécie, os principais sinais da leptospirose são os ligados à esfera reprodutiva, como abortos, natimortos, reabsorção fetal, nascimento de animais debilitados e infertilidade, podendo a fêmea necessitar de 3-6 coberturas para

\footnotetext{
${ }^{1}$ Médico Veterinário, Acadêmico do Curso de Mestrado em Sanidade Animal, Depatamento de Medicina Veterinária Preventiva e Patologia Animal, Universidade Estadual de Londrina (UEL).

${ }^{2}$ Médico Veterinário, Doutor, Professor Titular, Departamento de Medicina Veterinária Preventiva e Patologia Animal, UEL.

${ }^{3}$ Médico Veterinário, Doutor, Professor Titular, Departamento de Medicina Veterinária Preventiva e Patologia Animal, UEL, CP. 6001, 86051-970, Londrina, Paraná. E-mail: freitasj@sercomtel.com.br. Autor para correspondência.
} 
conceber (FAINE, 1982; ELLIS, 1984; ELLIS et al., 1985). Há ainda relatos de casos de mamite clínica e subclínica, com presença de flacidez de úbere e leite amarelado com estrias de sangue, ocasionando elevada redução na produção (SULLIVAN et al., 1970; ELLIS et al., 1986).

$\mathrm{Na}$ transmissão da leptospirose bovina, deve ser considerada a eliminação do microrganismo através da urina por um período prolongado, o que ocasiona a contaminação do meio ambiente e de outros animais (AMATREDJO et al., 1975; THIERMANN, 1984; ELLIS et al., 1981). Segundo TWIGG $\boldsymbol{e t}$ al. (1972), as leptospiras estão amplamente distribuídas entre animais silvestres, o que os torna prováveis fontes de infecção para animais domésticos. Como o quadro clínico de leptospirose é comum a outras patologias infecciosas da esfera reprodutiva, uma vez observados os sinais clínicos o diagnóstico é confirmado através de exames laboratoriais. Dentre os diversos testes já padronizados para diagnóstico laboratorial de leptospirose, LILEMBAUM (1995) afirma que o teste de soroaglutinação microscópica com antígenos vivos é, sem dúvida, ainda o mais utilizado por pesquisadores de todo o mundo para diagnóstico da leptospirose bovina.

O objetivo principal deste trabalho foi determinar a freqüência de infecção leptospírica através da pesquisa de anticorpos contra 22 sorotipos de Leptospira interrogans (L. interrogans) em fêmeas bovinas, adultas de 14 propriedades produtoras de leite tipo $\mathrm{B}$, da região de Londrina-Pr.

\section{MATERIAL E MÉTODOS}

Foram estudadas14 propriedades produtoras de leite tipo $\mathrm{B}$, da região de Londrina-Pr. Em 13 propriedades, os animais eram da raça Holandesa e em uma, da raça Jersey. As propriedades foram denominadas de $\mathrm{A}$ a $\mathrm{N}$, sendo que apenas as propriedades A e D faziam compra e venda de animais (propriedades abertas), enquanto as demais propriedades realizavam somente a venda (propriedades fechadas). Todas as propriedades utilizavam inseminação artificial e foram selecionadas por apresentarem histórico de abortos e infertilidade das fêmeas. Nenhuma propriedade vacinava os animais contra leptospirose. Foram colhidas amostras de sangue de 1253 fêmeas bovinas com idade a partir de 15 meses, no período de agosto de 1995 a agosto de 1997. Os soros obtidos foram estocados $\mathrm{a}-20^{\circ} \mathrm{C}$ até a realização do exame. $\mathrm{O}$ exame sorológico foi realizado usando o teste de microaglutinação rápida, descrito por RYU (1970). Foram utilizadas como antígenos culturas vivas de 22 sorotipos de $\boldsymbol{L}$. interrogans, com 5-10 dias de incubação a $28^{\circ} \mathrm{C}$, correspondendo a 17 sorogrupos (tabela 1), mantidas em meio de EllinghausenMcCullough-Johnson-Harris (EMJH) modificado com albumina bovina. Os soros suspeitos foram diluídos previamente a 1:50 em PBS $\mathrm{pH} 7,2$, e a esses foi adicionado a mesma quantidade de antígeno. Os tubos contendo a mistura foram incubados por 12 minutos, à temperatura ambiente. Com uma alça de platina, uma gota de cada mistura foi colocada sobre uma lâmina e a leitura realizada em microscópio de campo escuro, de acordo com MYERS (1985). Todos os soros que apresentaram $2+$ de aglutinação na diluição 1:100 foram considerados positivos. Após essa triagem, os soros positivos foram diluídos e examinados até encontrar os títulos finais. Em todos os soros examinados para leptospirose também foi realizado o teste de soroaglutinação rápida para diagnóstico de brucelose, utilizando antígeno produzido pelo TECPAR-Pr.

\section{RESULTADOS}

Das 14 propriedades estudadas, 10 (71,43\%) apresentaram animais com evidência sorológica de infecção por L. interrogans. Em 166 $(13,25 \%)$, dos 1253 animais testados, foram encontrados títulos de anticorpos $\geq 100$ contra

Tabela 1 - Sorotipos utilizados para a realização do teste de microaglutinação rápida.

\begin{tabular}{|c|c|c|}
\hline Sorogrupos & Sorotipos & Amostras \\
\hline \multirow[t]{2}{*}{ Australis } & australis & Ballico \\
\hline & bratislava & Jez Bratislava \\
\hline \multirow[t]{3}{*}{ Autumnalis } & autumnalis & Akiyami A \\
\hline & butembo & Butembo \\
\hline & fortbragg & Fort Bragg \\
\hline Ballum & castellonis & Castellon 3 \\
\hline Bataviae & bataviae & Van Tienen \\
\hline Canicola & canicola & Hond Utrecht IV \\
\hline Celledoni & whitcombi & Whitcombi \\
\hline Cynopteri & cynopteri & $3522 \mathrm{C}$ \\
\hline Djasiman & sentot & Sentot \\
\hline Grippotyphosa & grippotyphosa & Moskva V \\
\hline Hebdomadis & hebdomadis & Hebdomadis \\
\hline \multirow[t]{2}{*}{ Icterohaemorrhagiae } & icterohaemorrhagiae & RGA \\
\hline & copenhageni & M-20 \\
\hline Panama & panama & CZ $214 \mathrm{~K}$ \\
\hline Pomona & pomona & Pomona \\
\hline Pyrogenes & pyrogenes & Salinem \\
\hline \multirow[t]{2}{*}{ Sejroe } & hardjo & Hardjoprajitno \\
\hline & wolffi & 3705 \\
\hline Shermani & shermani & LT 821 \\
\hline Tarassovi & tarassovi & Perepelicin \\
\hline
\end{tabular}


leptospira. Nas propriedades estudadas, foram observados percentuais de animais reagentes variando de 4,7 a 51,06 (tabela 2). No presente estudo, foram detectados anticorpos contra 11 sorotipos de L. interrogans. Anticorpos contra o sorotipo icterohaemorrhagiae foram verificados em $48(28,91 \%)$ dos animais reagentes, seguido pelos sorotipos pomona 35 (21,08\%), bataviae 28 $(16,87 \%)$, autumnalis $24(14,46 \%)$, canicola 19 $(11,44 \%)$, hardjo 18 (10,84\%), bratislava 17 (10,24\%), butembo 13 (7,83\%), pyrogenes 12 $(7,22 \%)$, hebdomadis $11(6,63 \%)$ e wolffi 10 $(6,02 \%)$ (tabela 3). Em 110 (66,26\%) animais, foram detectados anticorpos contra 01 sorotipo, enquanto que $56 \quad(33,73 \%)$ apresentaram anticorpos contra 02 ou mais sorotipos simultaneamente. Anticorpos nas diluições de 1:100 e 1:200 foram observados em $163(98,19 \%)$ dos animais considerados positivos, enquanto apenas $03(1,81 \%)$ apresentaram anticorpos nas diluições de 1:400 e 1:800. A frequiência de sorotipos detectados através da prova de microaglutinação rápida, em cada propriedade estudada, está representada na tabela 4. Todas as fêmeas bovinas testadas foram negativas para brucelose.

Tabela 2 - Distribuição do número de fêmeas bovinas, adultas examinadas e reagentes positivos à prova de microaglutinação rápida para Leptospira interrogans, em 14 propriedades, produtoras de leite tipo $\mathrm{B}$, da região de Londrina-Paraná-Brasil (1995-1997).

\begin{tabular}{|c|c|c|c|}
\hline \multirow{2}{*}{ Propriedades } & \multirow{2}{*}{$\begin{array}{c}\mathrm{N}^{\mathrm{o}} \text { de animais } \\
\text { examinados }\end{array}$} & \multicolumn{2}{|c|}{ Animais reagentes* } \\
\hline & & Positivos & $\%$ \\
\hline A & 195 & 22 & 11,28 \\
\hline B & 47 & 24 & 51,06 \\
\hline $\mathrm{C}$ & 145 & 23 & 15,90 \\
\hline D & 251 & 27 & 10,75 \\
\hline $\mathrm{E}$ & 64 & 03 & 4,70 \\
\hline $\mathrm{F}$ & 32 & 11 & 34,40 \\
\hline $\mathrm{G}$ & 15 & 04 & 26,70 \\
\hline $\mathrm{H}$ & 64 & 25 & 39,06 \\
\hline I & 68 & 10 & 14,70 \\
\hline J & 131 & 17 & 12,98 \\
\hline $\mathrm{K}$ & 33 & 0 & 0 \\
\hline $\mathrm{L}$ & 21 & 0 & 0 \\
\hline M & 152 & 0 & 0 \\
\hline $\mathrm{N}$ & 35 & 0 & 0 \\
\hline Total & 1253 & 166 & 13,25 \\
\hline
\end{tabular}

*Títulos de anticorpos $\geq 100$.
Tabela 3 - Porcentagens de fêmeas bovinas, adultas reagentes à prova de microaglutinação rápida para diferentes sorotipos de Leptospira interrogans, de 14 propriedades produtoras de leite tipo B, da região de Londrina-Paraná-Brasil (19951997).

\begin{tabular}{lccc}
\hline \multicolumn{1}{c}{ Sorotipos } & $\begin{array}{c}\mathrm{N}^{\mathrm{o}} \text { de Fêmeas } \\
\text { bovinas reagentes }\end{array}$ & \% TE** & $\% \mathrm{TR}^{* * *}$ \\
& & & \\
\hline icterohaemorrhagiae & 48 & 3,83 & 28,91 \\
pomona & 35 & 2,79 & 21,08 \\
bataviae & 28 & 2,23 & 16,87 \\
autumnalis & 24 & 1,91 & 14,46 \\
canicola & 19 & 1,52 & 11,44 \\
hardjo & 18 & 1,44 & 10,84 \\
bratislava & 17 & 1,36 & 10,24 \\
butembo & 13 & 1,04 & 7,83 \\
pyrogenes & 12 & 0,96 & 7,22 \\
hebdomadis & 11 & 0,88 & 6,63 \\
wolffi & 10 & 0,80 & 6,02 \\
& & & \\
\hline
\end{tabular}

*Títulos de anticorpos $\geq 100$

**TE-em relação ao total de fêmeas bovinas, adultas (1253) examinadas.

***TR-em relação ao total de fêmeas bovinas, adultas (166) reagentes.

\section{DISCUSSÃO}

Os resultados deste trabalho mostram em $166(13,25 \%)$ fêmeas bovinas, adultas de 10 $(71,43 \%)$, das 14 propriedades pesquisadas, a presença de anticorpos contra diferentes sorotipos de Leptospira interrogans. Estes resultados coincidem com os encontrados por ROCHA \& PEREIRA (1987) em Portugal, FONTAINE et al. (1988) na França e GIRIO \& MATHIAS (1989) no Brasil, os quais encontraram respectivamente $13,3 \%, 20,7 \%$ e $18,98 \%$ de bovinos reagentes para leptospira. Os resultados obtidos neste trabalho diferem de MILLER et al. (1991) que, pesquisando bovinos de abatedouros de 49 estados dos EUA, encontraram 49\% de positivos; e de LILENBAUM et al. (1995), no Brasil, que detectaram reações positivas em $68,4 \%$ dos soros de vacas com problemas reprodutivos. As diferenças, obtidas pelos autores acima citados em relação a este trabalho, podem ter ocorrido, pois esses autores selecionaram apenas animais com problemas reprodutivos, enquanto neste trabalho não foram selecionados animais, mas sim propriedades com histórico de problemas reprodutivos. Os resultados obtidos neste trabalho, no que se referem aos sorotipos mais freqüentemente detectados (icterohaemorrhagiae e pomona), assemelham-se em parte, aos encontrados na década de 70 no Brasil, onde se observava na maioria dos 
Tabela 4 - Distribuição de anticorpos detectados contra sorotipos de L.interrogans na prova de microaglutinação rápida em 14 propriedades produtoras de leite tipo B, da região de Londrina-Paraná (1995-1997).

\begin{tabular}{|c|c|c|c|c|c|c|c|c|c|c|c|c|c|c|c|c|c|c|c|c|c|c|c|}
\hline \multirow{2}{*}{$\begin{array}{c}\text { Proprie- } \\
\text { dades }\end{array}$} & \multirow{2}{*}{$\begin{array}{c}\mathrm{N}^{\circ} \text { de } \\
\text { fêmeas } \\
\text { bovinas } \\
\text { adultas }\end{array}$} & \multicolumn{2}{|c|}{ L.hardjo } & \multicolumn{2}{|c|}{ L.wolffi } & \multicolumn{2}{|c|}{ L.bratislava } & \multicolumn{2}{|c|}{ L.canicola } & \multicolumn{2}{|c|}{ L.pyrogenes } & \multicolumn{2}{|c|}{ L.bataviae } & \multicolumn{2}{|c|}{ L.autumnalis } & \multicolumn{2}{|c|}{ L.pomona } & \multicolumn{2}{|c|}{ L.hebdomadis } & \multicolumn{2}{|c|}{$\begin{array}{l}\text { Licterohae- } \\
\text { morrhagiae }\end{array}$} & \multicolumn{2}{|c|}{ L.butembo } \\
\hline & & reag* & $\%$ & reag & $\%$ & reag & $\%$ & reag & $\%$ & reag & $\%$ & reag & $\%$ & reag & $\%$ & reag & $\%$ & reag & $\%$ & reag & $\%$ & reag & $\%$ \\
\hline B & 47 & 0 & 0 & 0 & 0 & 0 & 0 & 4 & 8,51 & 0 & 0 & 0 & 0 & 5 & 10,64 & 7 & 14,89 & 8 & 17,02 & 7 & 14,89 & 0 & 0 \\
\hline C & 145 & 0 & 0 & 0 & 0 & 3 & 2,07 & 2 & 1,38 & 7 & 4,83 & 3 & 2,07 & 1 & 0,69 & 4 & 2,76 & 0 & 0 & 17 & 11,72 & 0 & 0 \\
\hline $\mathrm{F}$ & 32 & 0 & 0 & 0 & 0 & 1 & 3,13 & 0 & 0 & 2 & 6,25 & 1 & 3,13 & 1 & 3,13 & 0 & 0 & 0 & 0 & 9 & 28,13 & 0 & 0 \\
\hline G & 15 & 0 & 0 & 0 & 0 & 0 & 0 & 0 & 0 & 1 & 6,67 & 0 & 0 & 3 & 20,0 & 1 & 6,67 & 0 & 0 & 0 & 0 & 0 & 0 \\
\hline $\mathrm{H}$ & 64 & 0 & 0 & 0 & 0 & 0 & 0 & 5 & 7,81 & 0 & 0 & 4 & 6,25 & 3 & 4,69 & 3 & 4,69 & 0 & 0 & 8 & 12,50 & 13 & 20,31 \\
\hline I & 68 & 0 & 0 & 0 & 0 & 1 & 1,47 & 1 & 1,47 & 0 & 0 & 5 & 7,35 & 1 & 1,47 & 3 & 4,41 & 0 & 0 & 1 & 1,47 & 0 & 0 \\
\hline M & 152 & 0 & 0 & 0 & 0 & 0 & 0 & 0 & 0 & 0 & 0 & 0 & 0 & 0 & 0 & 0 & 0 & 0 & 0 & 0 & 0 & 0 & 0 \\
\hline $\mathrm{N}$ & 35 & 0 & 0 & 0 & 0 & 0 & 0 & 0 & 0 & 0 & 0 & 0 & 0 & 0 & 0 & 0 & 0 & 0 & 0 & 0 & 0 & 0 & 0 \\
\hline
\end{tabular}

Títulos de anticorpos $\geq 1: 100$

trabalhos a predominância do sorotipo pomona (REIS et al., 1973; CORDEIRO et al. , 1975; WILLIANS et al., 1975; VAZ \& OLIVEIRA, 1977; ÁVILA et al., 1978 e MOREIRA et al. 1979). Este sorotipo foi considerado por ZAMORA \& RIEDEMANN (1978) como um dos principais responsáveis por problemas reprodutivos em bovinos no Chile; embora as porcentagens apresentadas na tabela 3 , em relação ao total de fêmeas bovinas, adultas examinadas sejam baixas, tanto para o sorotipo icterohaemorrhagiae $(3,83 \%)$ como para o sorotipo pomona $(2,79 \%)$, deve-se ressaltar a importância dos valores obtidos para esses sorotipos $(28,91 \%$ e $21,08 \%$ respectivamente) quando analisados em relação ao total de animais reagentes. Os resultados deste trabalho mostram, ainda, que uma grande porcentagem dos animais reagentes apresentaram títulos de anticorpos $\geq 100$ contra os sorotipos bataviae e autumnalis, sorotipos que têm sido isolados de outros animais domésticos, silvestres e/ou sinantrópicos (SANTA ROSA et al., 1972; BIANCHI, 1984; ELLIS, 1986; TAYLOR $\boldsymbol{e t}$ al., 1991). Os bovinos podem se infectar com qualquer dos sorotipos de leptospiras patogênicas que existam no seu meio ambiente, podendo esta infecção ocorrer direta ou indiretamente através de 2 fontes: de outros bovinos portadores ou outros hospedeiros que habitem o mesmo ambiente (ELLIS et al., 1976).
Os diferentes sorotipos foram classificados por ELLIS (1984) em amostras adaptadas e mantidas pelos bovinos, e amostras não adaptadas que causam infecções acidentais, pois são mantidas por outras espécies domésticas, silvestres e/ou cinantrópicos. Assim, os anticorpos detectados neste trabalho, contra os sorotipos icterohaemorrhagiae, pomona, bataviae e autumnalis entre outros, parecem estar relacionados a infecções acidentais devido ao contato direto ou indireto dos bovinos com outras espécies animais que atuam como reservatórios destes sorotipos. A partir da década de 80, pesquisadores de vários países, inclusive do Brasil, têm verificado, principalmente através de provas sorológicas, a predominância do sorotipo hardjo em bovinos (RIBEIRO et al., 1988; MILLER et al., 1991; MOREIRA et al., 1993; BROD et al., 1995; RICHARDSON, 1995; TEDESCO, 1997). Este sorotipo foi considerado como uma amostra adaptada e mantida pelo próprio bovino (ELLIS, 1984), e tem sido, dentre os sorotipos de L. interrogans, o maior responsável por problemas reprodutivos nessa espécie animal (ELLIS, 1984; MOREIRA et al., 1994).

Neste trabalho, anticorpos contra o sorotipo hardjo foram detectados somente em 18 animais de 2 propriedades. ELLIS et al. (1981) e MOREIRA et al. (1994) afirmaram que a transmissão direta 
entre bovinos seria o mecanismo mais importante para a disseminação do sorotipo hardjo entre animais e rebanhos. Coincidentemente essas duas propriedades eram as únicas que realizavam a compra freqüente de animais, sendo consideradas propriedades abertas e, portanto, a entrada de animais seria, provavelmente, a responsável pela introdução desse sorotipo nestas propriedades.

\section{FONTE DE AQUISIÇÃO}

Antígeno para diagnóstico de brucelose: TECPARInstituto de Tecnologia do Paraná. Rua dos Funcionários, $1357-$ Curitiba-Pr. CEP-80035-050.

\section{REFERÊNCIAS BIBLIOGRÁFICAS}

AMATREDJO, A., CAMPBELL, R.S.F., PATH, M.R.C. Bovine leptospirosis. Veterinary Bulletin, v. 45, n. 12, p. 875-891, 1975.

ÁVILA, F.A., COSTA, A J., MORAES, F.R., et $\boldsymbol{a l}$. Pesquisa de aglutininas antileptospira em soros de bovinos no município de Jaboticabal, Brasil. Científica, v. 6, n. 3, p. 451-453, 1978.

BIANCHI, L. The Pavia Center for study and diagnosis of leptospirosis. Bollettino Instituto Sieroter Milan, v. 63, n. 3, p. 262-266, 1984

BROD, C.S., MARTINS, L.F.S., NUSSBAUM, J.R., $\boldsymbol{e} t \boldsymbol{a l}$. Leptospirose bovina na região sul do Estado do Rio Grande do Sul. A Hora Veterinária, n. 84, p. 15-20, 1995.

CORDEIRO, F., GUIDA, H.G., RAMOS, A.A., et al. Aglutininas antileptospira em soros de bovinos do Estado do Rio de Janeiro. Pesquisa Agropecuária Brasileira, v. 10, p. 9-19, 1975.

ELLIS, W.A., MICHNA, S.W. Bovine leptospirosis: A serological and clinical study. Veterinary Record, n. 99, p. $387-391,1976$

ELLIS, W.A., O'BRIEN, J.J., CASSELLS, J.A. Role of the cattle in the maintence of $\boldsymbol{L}$. interrogans serovar hardjo infection in Northern Ireland. Veterinary Record, n. 108, p. 555-557, 1981.

ELLIS, W.A. Bovine leptospirosis in the tropics: prevalence, pathogenisis and control. Preventive Veterinary Medicine, v. 2 , p. $411-421,1984$.

ELLIS, W.A., O'BRIEN, J.J., CASSELLS, J.A., et al. Excretion of L. interrogans serovar hardjo following calving or abortion. Research Veterinary Science, v. 39, p. 296-98, 1985.

ELLIS, W.A. Leptospirosis. Journal of Small Animal Practice, v. 27 , p. 683-692, 1986.

FAINE, S. Guidelines for the control of leptospirosis. 2. ed. Geneva: World Health Organization, 1982. $171 \mathrm{p}$

FONTAINE, A., GANIERE, J.P., QUINIOU, M.A., $\boldsymbol{e} t \boldsymbol{a l}$. Prevalence des anticorps antileptospires chez les bovins de Loire-Atlantique: II- Evolution des titres serologiques dans des exploitations infectées. Recueil de Médicine Vétérinaire, v. 164, n. 8-9, p. 617-622, 1988.

GIORGI, W., TERUYA, J.M., SILVA, A.S., et al. Leptospirose: Resultados das soroaglutinações realizadas no Instituto Biológico de São Paulo durante os anos de 1974-1980. Biológico, São Paulo, v. 47, n. 11, p. 299-309, 1981.

GIRIO, R.J.S., MATHIAS, L.A. Ocorrência de leptospirose em rebanhos bovinos produtores de leite tipo $\mathrm{B}$ na região Norte do Estado de São Paulo. Ciências Veterinárias, v. 3, n. 1, p. 3-5, 1989.

LILENBAUM, W. Atualização em leptospirose bovina. Revista Brasileira de Medicina Veterinária, Niterói, v. 18, n. 1, p. 9-13, 1995

LILENBAUM, W., SANTOS, M.R.C., BARBOSA, A.V. Leptospirose em reprodução animal: II - Bovinos do Estado do Rio de Janeiro, Brasil. Revista Brasileira de Ciências Veterinárias, Niterói, v. 2, n. 1, p. 1-6, 1995.

MILlER, D.A., WILSON, M.A., BERAN, G.W. Survey to estimative prevalence of Leptospira interrogans infection in mature catlle in the United States. American Journal of Veterinary Research, v. 52, n. 11, p. 1761-1768, 1991.

MOREIRA, E.C., SILVA, J.A., VIANA, F.C., et al. Leptospirose bovina: I Aglutininas antileptospiras em soros sangüíneos de bovinos em Minas Gerais. Arquivos da Escola de Veterinária da_UFMG, Belo Horizonte, v. 31, n. 3, p. 375-388, 1979.

MOREIRA, E.C., MORAIS, M.H.F., HADDAD, J.P.A., et al. Surto de leptospirose em bovinos leiteiros de Minas Gerais. In: CONGRESSO BRASILEIRO DE REPRODUÇÃO ANIMAL, Anais... Belo Horizonte, 1993, p. 192.

MOREIRA, E.C. Avaliação de métodos para erradicação de leptospirose em bovinos leiteiros. Belo Horizonte, MG. 110 p. Tese (Doutorado) - Curso de Pós-graduação em Ciência Animal, UFMG, 1994.

MYERS, D. Leptospirosis: manual de métodos para el diagnostico de laboratório. Buenos Aires: Centro Panamericano de Zoonosis, OPS/OMS, 1985. (Nota técnica 30).

REIS, R., RYU, E., PENA, C.M. Pesquisa de aglutininas antileptospiras em bovinos e suínos em Minas Gerais, Brasil. Arquivos da Escola de Veterinária da UFMG, Belo Horizonte, v. 25 , p. $11-13,1973$.

RIBEIRO, S.C.A., GOUVEIA, M.A.V., SILVA, P.L., $\boldsymbol{e t}$ al. Levantamento sorológico em dois surtos de leptospirose bovina em Uberlândia, Triângulo Mineiro. Arquivos Brasileiros de Medicina Veterinária e Zootecnia, Belo Horizonte, v. 40 , n. 6 , p. $415-423,1988$.

RICHARDSON, G.F., SPANGLER, E., MACAULAY, E.B.A serological survey of four Leptospira serovars in dairy cows on Prince Edwar Island. Canadian Veterinary Journal, v. 36 , n. 12 , p. $769-770,1995$.

ROCHA, T., PEREIRA, M.C. Leptospirosis in Portugal: Serological evidence of leptospiral agglutinins in brucellosis seronegative bovines. Israel Journal Veterinary Medicine, v. 43, n. 4, p. 313-322, 1987.

RYU, E. Rapid microscopic agglutination test for leptospira without non-specific reaction. Bulletin Office International Epizooties, v. 73, n. 1-2, p. 49-58, 1970. 
SALMAN, M.D., HERNANDEZ, J.A., BRAUN, I. A seroepidemiological study of live bovine diseases in dairy farms of the coastal region of Baja California, Mexico. Preventive Veterinary Medicine, v. 9, p. 143-153, 1990.

SANTA ROSA, C.A., SUlZER, C.R., CASTRO, A.F..P. A new leptospiral serotype in the bataviae group, isolated in São Paulo, Brazil. American Journal Veterinary Research, v. 33 , n. 8, p. 1719-1720, 1972.

SULLIVAN, N.D., CALLAN, D.P. Isolation of leptospira hardjo from cows with mastitis. Australian Veterinary Journal, v. 46 , p. $537-539,1970$

TAYLOR, K.D., TURNER, L.H., EVERARD, J.D. Leptospires in rattus spp on Barbados. Journal Tropics Medicine Hygiene, v. 94, n. 2, p. 102-103, 1991

TEDESCO, L.A. Leptospirose: uma doença que se expande e assusta. Balde Branco, São Paulo, v. 33, n. 395, p. 44-46, 1997.
THIERMANN, A.B. Leptospirosis: Current developments and trends. Journal American Veterinary Medical Association, v. 184, n. 6 , p. $722-5,1984$.

TWIGG, G.I., HUGHES, D.M., McDIARMID, A. Leptospiral antibodies in dairy cattle: some ecological considerations. Veterinary Record, v. 90, p. 598-602, 1972.

VAZ, A.K., OLIVEIRA, S.J. Títulos aglutinantes para leptospira em touros usados em inseminação artificial no Rio Grande do Sul. Boletim do Instituto de Pesquisas Veterinárias Desidério Finamor, Porto Alegre, p. 23-26, 1977.

ZAMORA, J., RIEDEMANN, S. Aborto bovino por leptospira, un grave problema en el sur del país. Archivos de Medicina Veterinaria, v. 10, p. 67-68, 1978.

WILLIANS, H.A., OLIVEIRA, S.J., RIBEIRO, C.A.O. Leptospirose como causa de aborto em um rebanho bovino no Rio Grande do Sul. Boletim do Instituto de Pesquisas Veterinárias Desidério Finamor, Porto Alegre, v. 3, p. 73-81, 1975.

Ciência Rural, v. 29, n. 2, 1999. 